\title{
Change in Managers' Conceptions of Human Resources in Organisations: Outcomes of an Intervention
}

\author{
Alexis Rydell ${ }^{1}$, Ing-Marie Andersson ${ }^{1}$ \& Ann Hedlund ${ }^{1}$ \\ ${ }^{1}$ School of Technology and Business Studies, Dalarna University, Sweden \\ Correspondence: Alexis Rydell, Dalarna University, Sweden. Tel: 46-23-778-925. E-mail: ary@du.se
}

Received: November 13, 2013

Accepted: December 5, 2013 Online Published: December 15, 2013

doi:10.5539/ijbm.v9n1p168

URL: http://dx.doi.org/10.5539/ijbm.v9n1p168

\begin{abstract}
Managers' conceptions of the importance of human resources are essential for creating 'attractive workplaces'. This paper examines an intervention method aimed at creating insight among managers in small and medium-sized enterprises (SMEs) concerning the potential of human resources. The intervention method is called Focus Group Attractive Work (FGAW) and was conducted at eight enterprises in Sweden. Based on the analysis, it is concluded that the intervention method seems to be thought-provoking and to facilitate changes in managers' conceptions of the importance of human resources, albeit to different degrees. The research contributes to conceptual change literature by being implemented in a new context. In addition, the research contributes to management and HR literature by evaluating an intervention method and its ability to change managers' conceptions of human resources.
\end{abstract}

Keywords: conceptual change, human resources, intervention, attractive workplaces, focus groups, SMEs

\section{Introduction}

It is often stressed that employees are an organisation's most important asset and that employees are the key to success. This is particularly so since organisations are completely dependent upon their workers. Nonetheless, many organisations have not treated their human resources as a capital investment (Luthans \& Youssef, 2004). From a strategic human resource management perspective, it is implied that treating employees as a source of strategic value contributes to a firm's performance and sustainability (Mayson \& Barrett, 2006, p. 448). Thus, employees should be seen not as a cost but as an asset and investment that can imply increased returns and contribute to the success of the organisation.

This way of arguing is in line with research on 'attractive workplaces', which reveals that attractive workplaces create increased possibilities of attracting individuals, as well as lower voluntary turnover and increased engagement among the workers (Åteg, Hedlund \& Pontén, 2004; Åteg \& Hedlund, 2011). Hence, 'attractive work' focuses on developing and utilising organisations' human resources.

Improving the attractiveness of the workplace is a continuous change process. The process can be described in six steps: (i) problem insight, (ii) local knowledge development, (iii) acceptance and expectations, (iv) choice and use of method, (v) implementations of routines and (vi) work environment improvements (Åteg, Andersson \& Rosén, 2005). The first step, problem insight, is a prerequisite for managers to take any decision on developing a change process. The fact that many organisations can become better at using human resources raised the question of the ability to influence managers' insight and thereby change their conceptions.

The purpose of this article is to analyse the effect of an intervention method aimed at creating prerequisites for changes in managers' conceptions about the significance of human resources for organisational development. The research question is as follows: to what degree does the intervention method facilitate change in managers' conceptions about the importance of human resources? The intervention method was used at eight small and medium-sized enterprises (SMEs) in Sweden. To understand and evaluate whether the intervention method contributed to changes in managers' conceptions, we turn to the concept of conceptual change.

\section{Conceptual Change}

Conceptual change theory started to grow in strength during the 1970s and 1980s (Sinatra \& Pintrich, 2003), inspired by Kuhn's (1962) classical theory on paradigms and paradigm shifts. In particular, Posner, Strike, Hewson and Gertzog's (1982) theory, with roots in the philosophy of science, has been seminal. Conceptual 
change is a mechanism that occurs, for instance, when an individual through learning moves from not understanding how something is working to understanding. Conceptual change is therefore seen as the very heart of learning (Mayer, 2002).

There are several somewhat different definitions of conceptual change. A few examples are learning that changes some existing conceptions (Chi, Slotta \& De Leeuw, 1994, p. 27), the process of removing misconceptions (Chi, 2002, p. 4) and the outcome of a complex cognitive as well as social process whereby an initial framework theory is restructured (Vosniadou, 2003, p. 377). However, the described definitions address a learner's transition from one state of knowledge to another.

Research on conceptual change lies at the intersection of three scientific fields: development cognitive psychology, history and philosophy of science, and science education (Rausanen \& Pöyhönen, 2013). The theory has gained wide acceptance, especially through its application in the context of science education (Ho, 2000). To date, conceptual change is perhaps one of the most studied fields within science education (Rusanen, 2013). In this field, scholars have focused on how students' scientific concepts and beliefs are restructured and reorganised. Important, however, is that 'misconceptions' of scientific phenomena and conceptual change exist for people of all ages (Boesdorfer, Lorsbach \& Morey, 2011), and as such, conceptual change is an on-going process throughout a person's lifetime (Thagard, 2012). Ho (2000) brings conceptual change theory into the field of staff development, starting with strategies of change, such as Argyris and Schön's (1974) theory of transition between theories-of-action; Posner, Strike, Hewson and Gertzog's (1982) theory of conceptual change; Lewin's (1947/1951) classical theory of social change and Shaw, Davis, Sidani-Tabbaa and McCarty's (1990) perspective of the psychological commitment of the teacher (Ho, 2000). All of these change theories are based on 'confrontation': they have posed a confrontation as the foremost and essential trigger for change to occur. Lewin talked about 'emotional stir-up' to unfreeze individuals from quasi-stationary equilibrium. Argyris and Schön outlined different types of dilemmas that could create the necessary tension to provide the momentum for moving forward. Both Posner et al. and Shaw et al. posited the psychological state of being 'dissatisfied' with the existing conceptions or state of affairs as the first condition for change (Ho, 2000). Argyris and Schön point out that there is a strong tendency toward consonance, preventing professionals from seeing the inadequacies in existing conceptions. Because of this resilience in the existing conceptions, they explicitly stressed the importance of making people aware of inadequacies through highlighting any discrepancies that might exist (Ho, 2000).

In an overview of conceptual change theories, Özdemire and Clark (2007) identify two broad theoretical perspectives: (1) knowledge-as-theory and (2) knowledge-as-elements. Many researchers within the knowledge-as-theory perspective have been inspired by Piagetian learning theory, where conceptual change is described using an analogy to Piaget's concepts of assimilation and accommodation and Kuhn's concepts of normal science and scientific revolutions. Within knowledge-as-theory, conceptual change is seen as occurring through revolutionary change in knowledge structures due to incommensurability or, as in Vosniadou (1994), as the evolution of mental models (Özdemire \& Clark, 2007). Radical changes do, however, not take place suddenly. Rather, they involve gradual and time-consuming processes of revision and restructuring of the entire network of beliefs and presuppositions (Taylor \& Kowalski, 2004; Özdemire \& Clark, 2007). The knowledge-as-element perspective emphasises that knowledge structures consist of multiple conceptual elements, such as facts, facets, narratives, concepts and mental models at various stages of development and sophistication (Özdemire \& Clark, 2007).

There are significant areas of agreement and overlap between the two theoretical perspectives. One such area is that much naive knowledge is highly resistant to change because of its entrenchment in everyday experiences (Özdemire \& Clark, 2007). However, there are also significant differences. One such difference that is highly relevant in the context of managers' conceptions exists in the view on the nature of change processes. Knowledge-as-theory perspectives often suggest revolutionary change, where current concepts are abandoned and replaced. Knowledge-as-elements perspectives propose a more evolutionary process without distinct phases or stages. Learning involves gradual eliminations, additions and organisation of elemental knowledge pieces where multiple contradictory ideas can coexist (Özdemire \& Clark, 2007).

One of the most influential theories in conceptual change is proposed by Posner, Strike, Hewson and Gertzog (1982) within the context of scientific education. The theory has roots in philosophy of science and states that conceptual change is analogous to the model of development and a radical shift in scientific beliefs within the community of scientists (Ho, 2000). The theory also corresponds to Piaget's concepts of assimilation and accommodation in describing two phases or levels of conceptual change (Özdemire \& Clark, 2007). In the first phase, assimilation, the individual's existing concepts are used to understand problems or explain phenomena. 
When the current concepts are insufficient or incapable of allowing the individual to successfully solve the problem, this may lead to dissatisfaction with the current conception, leading to conceptual change. However, the new scientific conception must also be intelligible, plausible and fruitful for conceptual change to occur (Posner, Strike, Hewson \& Gertzog, 1982). Hence, a way to initiate conceptual change is through creating a cognitive conflict, making the learner dissatisfied with the current conception (Özdemire \& Clark, 2007; Lee \& Byun, 2012). Importantly, though, is that the effect of cognitive conflict on individuals' conceptual change is linked to individuals' ability to feel the conflict presented to them (Hadjiachilleos, Valandies \& Angeli, 2013).

Vosniadou (1994) also distinguishes several types of conceptual change. The simplest form is enrichment, which involves the addition of new information to the individual's existing knowledge. Enrichment can occur when a person has no prior knowledge of what is being learned but does have some knowledge related to the topic. In this case, the to-be-learned knowledge is 'missing', so the learning is an 'adding process'. In addition, knowledge can be 'incomplete', and in those cases, a 'gap filling' of knowledge can occur. Both these cases are knowledge acquisition of the enrichment type (Chi, 2008, p. 61). Revision is the second type of conceptual change, required when the information to be acquired is inconsistent with beliefs, presuppositions or the structure of the theory. The third type of conceptual change, change of framework theory, is rather difficult to achieve because it involves reviewing presuppositions that are based on everyday experience and supported by years of confirmation (Vosniadou, 1994).

The theoretical perspective of conceptual change is applied here within a context where, to our knowledge, it has not previously been used. However, the conceptual change framework does seem to be suitable since it provides an analogy to creating insight in the significance of human resources for organisational sustainability where such understanding is lacking.

\section{Method and Materials}

This paper focuses on managers' conceptions about attractive work and the significance of human resources for organisations. A focus group method is used in an intervention to provide new information and knowledge to managers and possibly, when needed, to facilitate a process of conceptual change. The degree of conceptual change caused by the intervention method was thereafter evaluated in two steps. The intervention method was developed to be easy to understand, be quick to carry through and provide guidance for further development work. Focus Group Attractive Work (FGAW) gives a broad base for continuation built on dialogue and analyses at an individual level, including psychological and social dimensions (Andersson, Hedlund \& Rosén, 2010).

\subsection{The Focus Group Attractive Work}

Focus group is a behavioural and cognitive method that is well established within research. Its foundation is psychological and generally aims at information about the participants' perceptions and cognitive processes. By creating a confrontation through the provision of new, thought-provoking information, the focus group is believed to provide possibilities for conceptual change. Focus groups are an extension of individual interviews. Focus groups are acknowledged to have both positive and negative aspects, especially because the participants are expected to talk in a group. On the positive side is the fact that each individual can feel safe in numbers and is more likely to discuss and express feelings and reactions when others are sharing similar points of view. It is also possible that the participants will develop consensus (Stanton, 2005). Consequently, focus groups can add new knowledge and richness (Sobreperez, 2008). Another positive aspect of focus groups is that they 'can prove economical on time, for both the researchers and respondents, thus making it an efficient research method' (Grant \& Fitzgerald, 2005, p. 40). On the negative side, it may be difficult for individuals to express feelings or reactions that do not agree with the consensus (Stanton 2005).

The FGAW intervention method is based on the Attractive Work model ( $\AA$ teg \& Hedlund, 2011) and the Attractive Work process (Hedlund, Andersson \& Rosén, 2009). The ambition with the FGAW intervention method was that it should be easy to understand for the participants, quick to perform and provide concrete guidance for the manager to take a decision about a development process. This was believed to provide lasting value for the company. An additional and important requirement for the intervention method is that it depends not on any deep expert knowledge but on being understandable and usable by process leaders with more general competence. The intervention method should be simple, rapid and effective to implement, including analysis and a report back to the company within one working day.

The FGAW intervention method addresses dimensions of attractive work. A group of employees, with support from a process leader familiar with the intervention method, discusses and sorts dimensions of attractive work according to their perceived importance for their work to be attractive. A group normally consists of three to six people and is preferably mixed regarding gender, age and department affiliation. Initially, the participants are 
given the idea that attractive work can be defined as a job that you want to have, that you will want to remain in and that you will be committed to. The group discusses what they see as attractive in their current work, what makes it attractive and what they can do to increase the attractiveness. The most important qualities in work are identified. A model of attractive work in the form of a tree (Åteg, Hedlund \& Pontén, 2004) is plotted on a whiteboard and used to support the discussion. Various dimensions of work are illustrated in the form of plastic-coated apples with magnets. The different steps in the FGAW intervention method are documented with photos of the whiteboard. The role of the process leader is to act as moderator, to give instructions where needed and to document the results. The process leader also reports the content of the process to the manager using photos and the whiteboard. The employees involved in the focus group are also invited to participate in this meeting.

\subsection{Selection of Companies}

Small and medium-sized companies in different industrial sectors in the Dalarna and Värmland region have been included in the study. A list of 830 companies was selected from Retriever, a Swedish database containing company information. In the order of the list of potential companies, they with fewer than 200 employees were contacted and asked whether they would be interested in participating in the study. Companies that have participated in research and development projects with the research group in recent years were excluded. In addition, companies describing well-developed HRM programs on their home pages were also excluded. In total, 40 companies were contacted, and the most common reasons for unwillingness to participate were lack of time, reduction of staff, a newly conducted staff investigation or no interested staff. The eight companies that agreed to participate had 17-170 employees (see Table 1). In total, the number of women respondents was less than the number of men.

Table 1. Participating companies

\begin{tabular}{llll}
\hline Company & Business & Employees & Focus Group \\
\hline 1 & Technical product development & 50 & 1 woman and 2 men \\
2 & $\begin{array}{l}\text { Production of fans for buildings and } \\
\text { industry }\end{array}$ & 150 & 1 woman and 3 men \\
& Production of skin care products & 170 & 2 women and 1 man \\
3 & Engineering workshop & 17 & 3 men \\
5 & Production of wood claddings and & 66 & 1 woman and 3 men \\
6 & furniture for public buildings & & 2 women and 2 men \\
7 & Production of knives and drills for ice & 100 & 2 women and 2 men \\
8 & Production of saw blades and knives for & 55 & \\
\hline
\end{tabular}

The researcher who contacted the company prepared by looking at the company's website, if one was available. The website gave important information about the company's production and organisation. It was also often possible to find the appropriate contact, in most cases the manager responsible for the company.

The conversation began with a presentation from the researcher. The project's aim of improving the company's capacity to maintain, develop and recruit staff was highlighted. After that, the manager was asked whether the company would be interested in testing a developing intervention method with the researchers. Such cooperation would also allow discussions about opportunities for development of the company to better utilise human resources at work. The companies that agreed to participate were given a brief description of the FGAW intervention method.

Some companies asked for more written information before they were ready to provide a response. In these cases, a brief written description of the FGAW intervention method was sent to the company. The manager was asked to select employees who would participate in the intervention method, choosing employees from different departments within the organisation and of both genders, as well as white-collar and 
blue-collar workers. In most cases, this was fulfilled; in one case, where no women worked at the organisation, only men took part. An agreement on an appropriate day was also made. The companies that declined to participate were questioned about their decision.

\subsection{Implementation}

On the empirical study day, two researchers visited the company. One of these served as the process leader and the other took detailed notes during the FGAW intervention method. A group of three to four selected employees participated. The first step in the FGAW method, which involved the collection of data, was conducted in the morning. The next step for the researcher was to put together the data before the process, and the results were presented and discussed with the company's manager in the afternoon. The employees were invited to participate and to give comments on the results. After that, the meeting turned into a discussion between the researchers and the manager about the results. The manager was asked to talk generally about the company and his/her impressions and conclusions of the information presented from the FGAW intervention method. Some documentation from the FGAW intervention method results was given to the manager. The visit ended with the manager answering some evaluation questions.

\subsection{Evaluations}

The effect of the FGAW intervention method was analysed in two steps. The first evaluation was conducted at the end of the study day and the second half a year after the study day. At the end of the study day, the process leaders asked the manager questions about the effect of the intervention method. The first question concerned the manager's change of knowledge about possibilities to recruit, retain and engage competent employees. He/she was asked to answer 'Yes' or 'No'. The second question concerned the manager's opinion about the company's development work to improve the possibility to recruit, retain and engage competent employees. The answering alternatives were (1) 'I did not see any need for development work one month ago', (2) 'I do not see any need for development work today', (3) 'I need more information to decide about continuation', (4) 'I am ready to start discussion about development work', (5) 'I am ready to decide about development work' and (6) 'I have decided about development work'. The third question concerned the degree to which the total amount of development activities at the company during the preceding year have aimed to recruit, retain and engage competent employees. The answering alternatives were 'none', 'less than 10\%', '10-20\%', '21-50\%', '51-80\%', '81-90\%', and 'more than $90 \%$ '. As a complement to the evaluation questions, notes were taken from the discussion with the manager.

The second evaluation was conducted as a phone interview by an experienced interviewer. The interviewer had previously not been involved with the intervention. This procedure was selected to get honest answers from the company managers and to increase objectivity. The phone interviews lasted for up to 25 minutes and were recorded and transcribed. The aim of the second evaluation was, first, to gather information, making it possible to analyse the outcome of the FGAW intervention method in terms of conceptual change, and second, to let the managers express their opinions about intervention and to measure any long-term effects of the intervention.

The questions asked can be grouped into three sections. The first section of questions is closely linked to the intervention method, including opinions about the method, the report from the study day, the results of the intervention method used and whether discussions or decisions were made about development work.

The second section includes three pairs of questions aimed at identifying the manager's conceptual change. The three pairs of questions were designed to correspond to the three forms of conceptual change according to Vosniadou (1994): enrichment, revision and change of framework theory. In the first pair, the respondent was asked whether the intervention method contributed any new information or knowledge (enrichment) and about the respondent's assessment of the possibility of the intervention method contributing new information or knowledge. The second pair concerned whether the intervention method contributed information that was thought-provoking or contributed to new thinking (revision) and the respondent's assessment of the possibility of the intervention method contributing in such a manner. The third pair of questions concerned whether the intervention method contributed new knowledge or information that required new ways of thinking (change of framework) and the respondent's assessment of the possibility of the intervention method contributing in such a way. The transcribed answers were sorted into three categories: 'not at all', 'to some extent' and 'to a major part'. 
Finally, in the third section, the manager was asked whether he/she would recommend the intervention method to a neighbouring company and at what price. The reason that the manager was asked about the price is that it can be taken as a signal of the perceived value of the outcomes of the intervention method. In total, eight managers were interviewed. One interview had technical problems and was not recorded. The data from the evaluations have been analysed by the researcher who transcribed the interviews, together with the other researchers involved in the study.

\section{Results}

\subsection{Evaluation 1}

Half of the managers said that they had changed their knowledge about possibilities to recruit, retain and engage competent employees (see Table 2). The other half said that they had not, but two of them said that the results confirmed earlier knowledge: one said that it raised thoughts and one said that new suggestions for solutions were raised. Half of the managers needed more information or further discussions before deciding about development work. One manager was ready to decide about development work, and three had already decided about development work. Half of the companies reported that between $21 \%$ and $50 \%$ of the total amount of development activities during the preceding year was aimed at recruiting, retaining and engaging competent employees; three managers reported less than $21 \%$ and one manager more than $90 \%$.

Table 2. Managers answer from evaluation 1

\begin{tabular}{|c|c|c|c|}
\hline Company & $\begin{array}{l}\text { 1. Manager's change of } \\
\text { knowledge }\end{array}$ & $\begin{array}{l}\text { 2. Need for HRM and } \\
\text { development activities (scale } \\
\text { 1-6) }\end{array}$ & $\begin{array}{l}\text { 3. Degree of HRM in } \\
\text { development activities }\end{array}$ \\
\hline 1 & No, but thoughts raised & $3-4$ & $21-50 \%$ \\
\hline 2 & Yes & 4 & $21-50 \%$ \\
\hline 3 & Yes & $3-4$ & $>90 \%$ \\
\hline 4 & Yes & 4 & $<10 \%$ \\
\hline 5 & Yes & 5 & $21-50 \%$ \\
\hline 6 & Not changed but confirmed & 6 & $21-50 \%$ \\
\hline 7 & Not changed but confirmed & 6 & $10-20 \%$ \\
\hline 8 & $\begin{array}{l}\text { No, but new solution } \\
\text { suggestions }\end{array}$ & 6 & $10-20 \%$ \\
\hline
\end{tabular}

The managers expressed the view that the participants had to think about the message from 'the apples' and that this raised many thoughts, which are positive effects of the intervention method. That the intervention method is pedagogical and gives a good overall view was reported by half of the managers. Two managers in particular said that the intervention method engages employees and gives a common base where employees are an important resource. Two HR managers expressed an interest in using the intervention method in the company's manager group. Other managers said that they could recommend the intervention method to other companies. At one company where the employees did not participate in the presentation of the results, the manager said at the beginning that it did not give any new information. On the other hand, the HR manager at the same company was satisfied and planned to work further. One manager expressed the possibility of continuing work with the intervention method as one alternative tool for development.

Some managers expected that the intervention method would determine whether the company was attractive or not. A wish from some managers was to have the possibility of discussing further steps to perform suggested development areas. Half of the companies said spontaneously that the process leaders were welcome to come back. 


\subsection{Evaluation 2}

In the second evaluation, the participating companies were interviewed via telephone. The participants' gender and position are described in Table 3 below.

Table 3. Managers answering evaluation 2

\begin{tabular}{lll}
\hline Company & Gender & Position \\
\hline 1 & Man & HR manager \\
2 & Woman & HR manager \\
3 & Woman & HR manager \\
$4^{*}$ & Man & Manager \\
5 & Man & HR manager (controller) \\
6 & Woman & HR manager \\
7 & Woman & HR manager \\
8 & Woman & HR manager \\
\hline
\end{tabular}

* The interview with Company 4 was not recorded due to technical problems.

The answers to the questions in section 1 concerning the intervention method were often short. In section 2, containing questions aimed at giving information on conceptual change, most managers gave clear answers. However, in several cases, the managers also gave information important to the analysis of the existence of conceptual change in section 1. Often, the managers gave longer descriptions of the outcomes of the intervention method while answering these questions. In the following text, all results are structured according to the order of the questions in the interviews.

\subsubsection{Section 1-Opinions on the Intervention Method}

Six managers expressed a high degree positive opinion toward the intervention method, and the seventh found it useful. The positive qualities of the intervention method are mostly due to the fact that it was perceived as easy to work with; the employees participating were given the chance to express themselves, and they were being listened to. Some managers indicated that the result from the discussions in some way confirmed what the managers claimed they already knew. One of the managers found it difficult to see the situation in which the intervention method should be used at her company since they had a well developed work environment. The top management at one company expressed their interest in participating in a focus group themselves.

The idea behind the intervention method was to generate a first 'insight' in the company regarding human resources. In some cases, the answers suggest that the manager had higher expectations for the outcomes of the intervention method. The manager wanted more thought-out and details in a continuous process. All of the managers had read the report, and at five of the companies, they also had other persons read it. Most of the companies read and discussed the report shortly after it was sent to them. Only one company, so far, has had further discussions about the results in the report. Another manager said that there was nothing wrong with the intervention method but that they had not prioritised following up on the discussions.

Five of the companies have discussed the results that came out of the intervention method. One company had not discussed it, and one did not answer the question. Half of the companies have used the results in their development work. One company has planned to work further with the results when the HR manager is back from parental leave. The last company has not given any answer. 


\subsubsection{Section 2 - Conceptual Change}

Table 4. Managers' answers concerning the FGAW intervention method's contribution and possibility for conceptual change (in evaluation 2)

\begin{tabular}{llll}
\hline Company & $\begin{array}{l}\text { Enrichment } \\
\text { Contribution/ }\end{array}$ & $\begin{array}{l}\text { Revision } \\
\text { Contribution/ }\end{array}$ & $\begin{array}{l}\text { Change of framework } \\
\text { Contribution/ } \\
\text { Possibility }\end{array}$ \\
\hline 1 & Possibility & $2 / 2$ \\
2 & $2 / 3$ & $3 / 3$ & $1 / 1$ \\
3 & $1 / 2$ & $1 / 1$ & $-/-$ \\
5 & $2 / 3$ & $2-3 / 2$ & $2 / 2-3$ \\
6 & $1 / 3$ & $3 / 3$ & $2 / 3$ \\
7 & $3 / 3$ & $3 / 3$ & $-/-$ \\
8 & $2 / 3$ & $2 / 3$ & $1 / 2$ \\
\hline
\end{tabular}

Note: The scale is $1-3$, where 1 is 'not at all', 2 is 'to some extent' and 3 is 'to a major degree'.

In connection to the first pair of questions (enrichment), most of the managers expressed the view that the intervention method could provide new information or knowledge concerning attractive work. The managers who experienced to a lesser degree the acquisition of new information or knowledge (see Table 4) needed to go further in analysing the results and making suggestions for developmental actions. However, one manager still said he was attracted to how the results were visualised in the intervention method.

A second manager also pointed out that it is the intervention method itself, rather than the information given by the participants in the focus group, that holds new information or contributes to new knowledge:

'...it is a new method where you can get, in a very concrete way, improvement measures...'

A third manager said, however, that it was the intervention method that provided new information on human resources, as the intervention method includes both information on which qualities the participants find important to prioritise and the arguments as to why:

'... you get a little bit more motives, you did not just get an answer but you also found out why. What was behind it...'

One manager came to see that the intervention method actually provided new information and saw a connection to recruitment and retention. For the manager, the intervention method provided insight that current working conditions are important for recruitment over a long term. For two managers, the answers are rather clear in that they did not perceive that the intervention method contributed new information or knowledge leading to enrichment for them.

However, in assessing the possibility of the intervention method to contribute new information or knowledge in general, all managers clearly believed that this was the case. The manager who was least confident in giving an affirmative answer said that it could be helpful for new managers since it is pedagogical.

In the second pair of questions concerning conceptual change (revision), most of the managers stated that the intervention method could provide new information and that the results hold the potential for being thought-provoking. However, this opinion was not shared by one of the managers. The thought-provoking information consists of several aspects, but one in particular that was highlighted by one manager is the positive feedback from the participants, commented upon thus:

'Yes, it was that that you get also positive feedback, and what you are good at, what we are doing well, and not only what we can be better at but also confirmation that you also might do well and the right things. Achievements. And that is equally important to get that.'

Another manager who at least partly agreed is aiming at how the organisation should move forward based on the information given by the participants. He was not quite satisfied with the information since he believes that the information needs to be further analysed to be actionable. Instead, the manager described the intervention method as a source of questions, potentially leading to insights. The manager stated that the intervention method was good for indicating some issues as a first step in an internal process. 
However, there are also answers that more explicitly indicate that the intervention method did not provide thought-provoking information or new ways of thinking. In addition, in answering the question on whether the intervention method holds the possibility of being thought-provoking or contributing to new ways of thinking in general, almost all of the managers seem to have agreed that this is the case. The intervention method was seen as fruitful, especially for managers with low pre-knowledge of the conditions at the company.

In the third pair of questions (change of framework), there are more mixed results among the managers concerning whether the intervention method contributed new knowledge or information that required new ways of thinking. Two managers did not feel that the intervention method contributed to new knowledge in taking advantage of the staff, and two managers could not answer the question. However, three other managers said that the intervention method contributed to new ways of thinking to some extent. The intervention method highlighted qualities that workers perceived as attractive and important in the workplace, which sometimes were contradictory to managers' previous beliefs.

In evaluating whether the intervention method in general holds any possibilities for contributing to new ways of thinking, there were also mixed results among the managers. Two managers said the intervention method holds the potential to create new ways of thinking, whereas others were more negative or did not answer the questions. Only one manager apparently was certain that this is the case. Another manager was more unsure, stating that the intervention method needs to be used as part of a larger development process in which the employees participate and management is ready to change based on the results.

\subsubsection{Section 3-Value of the Outcome}

Concerning the value of the outcomes of the intervention method, most managers were reluctant to give a price. Instead, the answers revealed difficulties in obtaining a straight answer. One such answer was due to lack of experience in purchasing consulting services. One manager said that it was difficult to answer since he was reluctant to engage consultants, as they always produce the result that the buyer wishes. The highest sum that was mentioned was 2,000 euros or 50 euros per participating employee depending on the size of the company and the number of participants.

\section{Conclusion}

The purpose of this paper is to analyse the effect of an intervention method aimed at creating prerequisites for changes in managers' conceptions about the significance of human resources for improving organisations. As stated initially, managerial functions should focus more on human resources, not least since engaged employees are the key to improving organisational performance (cf. Markos \& Sridevi, 2010). The FGAW intervention method used in this study seems to be a helpful tool in creating enrichment and revisions of conceptions concerning human resources and, as a consequence, facilitates managers in taking actions in deciding on development programs to improve organisations. The strength of the FGAW method is that it clearly visualises the participating employees' perspectives, a strength that almost all managers agreed was useful. The outcome was mixed, however, depending on the managers' previous experience.

Half of the managers stated, at the end of the implementation day (first evaluation), that they had changed knowledge about human resources. Drawing on Vosniadou's (1994) notion of conceptual change, we can distinguish different levels of conceptual change. The simplest form of conceptual change is enrichment, which involves the addition of new information to an individual's existing knowledge. The next form is revision, which is required when the information to be acquired is inconsistent with beliefs, presuppositions or the structure of the theory. The third form of conceptual change, change of framework theory, involves reviewing presuppositions that are based on everyday experience and supported by years of confirmation. Our analysis shows that more than half of the managers found that the FGAW intervention method contributed to enrichment or revision of knowledge to a major degree. Some managers said that the intervention method had 'confirmed' their thoughts precisely. However, it could be assumed that even such confirmation of current conceptual beliefs may facilitate actions for decision making on human resources since it strengthens current assumptions. In addition, the most radical form in Vosniadou's (1994) conceptual change theory, change of framework, was only experienced to some extent by three of the managers. This is not surprising since many of the managers had long experience of being in a managerial position and thus had some pre-knowledge concerning these topics. In summary, the vast majority of the managers indicated that the intervention method to some or a major degree contributes to enrichment and revision of knowledge. This is an interesting development according to evaluation 1 , and it indicates that time and documentation are important factors for changes of conception.

Some managers expected that the intervention method would determine whether the company was attractive or not. Others wanted the intervention method to go one step further and make suggestions for improvements in the 
human factor at the company. However, the purpose of this study was not to make suggestions for improvements at the company but to increase the knowledge and awareness (insight) among the managers about the importance of human resources for developing a successful and attractive organisation. In this regard, we can conclude that the FGAW intervention method has most likely contributed to increased knowledge among the managers and thus facilitated a decision process concerning the human resource. The results show that several managers changed their conceptions about the importance of human resources after the intervention, albeit to different degrees.

The research contribution to the existing literature is twofold: it contributes to the conceptual change literature by being implemented in a new context, but also it contributes to management and HR literature by evaluating an intervention method and its ability to change managers' conceptions of human resources.

\subsection{Managerial Implications}

The managerial implication of the results of this study can be stated as follows: (1) managers need to be open and provide time for though-provoking intervention methods. We live in a rapidly changing world, and as a result, changes in conceptions are an on-going process throughout a lifetime (Thagard, 2012). As such, the ability to cope with changes depends on having sufficient knowledge. Indeed, old conceptions are not always the answer to new competitive challenges, especially not in times when enterprises are perpetually under intense global competition. (2) Human resources should be seized. Employees are the key to success because organisations competitiveness depends on their efforts. Indeed, engaged employees contribute to improved organisational performance (Markos \& Sridevi, 2010). (3) HR professionals should be seen as strategic partners (cf. Ulrich, 1997). Top management should focus on human resources and comprehend HR as a strategic partner in the drive for organisational development.

\subsection{Limitations and Suggestions for Further Research}

There are several limitations to this study. First, the study is limited to the engineering sector in Sweden. Therefore, it should be noted that there has been a long tradition of cooperation between management and labour in Sweden (cf. Rydell \& Wigblad, 2011). In addition, firms in Sweden are generally positive about collaboration with researchers, which makes it comparably easy to get access and carry through intervention methods. More importantly, the expected outcomes of the intervention method depend upon the organisation's insufficient knowledge of how to handle human resources. We focused on SMEs, which we expected (after studying their Web pages) to have an underdeveloped program for work environment and human resource policies. Several of those enterprises did not, for instance, have an HR department. Larger enterprises with HR departments may have more developed programs for development work and HR policies. As a result, managers at larger enterprises may have more knowledge, so the results of the intervention method may be different. The identity of the participants in the focus groups may also have affected the outcomes since it was the managers who decided which workers would participate in the FGAW process. The focus group itself cannot give a holistic picture of what is 'attractive' and 'unattractive' at the enterprise. However, since the focus groups were heterogenically constructed, it is assumed that they offer some indication.

Though a large amount of intervention research has been conducted at enterprises, there is still, to date, a lack of intervention methods aiming at creating conceptual change among managers. Therefore, further research should focus on developing additional intervention methods that can be a tool in the process of changing managers' conception about human resources and, consequently, contribute to organisational development. Moreover, longitudinal studies that analyse the long-term effects of intervention methods that aim at changing managers' conceptions are needed. Thus, further research should not only evaluate the implemented intervention method but also its long-term effect for the organisation.

\section{Acknowledgements}

First and foremost, we are deeply grateful to our colleague Dr Mattias Åteg (1972-2011), who tragically passed away during the early stage of this research. We are also grateful to Professor Gunnar Rosén for his participation in designing this study, Erik Flemström for his participation as a process leader and Marit Lundström for participating in conducting evaluation interviews. The research has been financed by the European Regional Development Fund and the Regional Cooperation Council of Dalarna, Sweden.

\section{References}

Andersson, I. M., Hedlund, A., \& Rosén, G. (2010). Ökad förståelse bland företagsledare för nyttan av utvecklingsinsatser inom arbetsmiljöområdet (Increased understanding among business managers for the benefit of development in work enviroment). Arbetsrapport Högskolan Dalarna 2010:10, Falun. 
Boesdorfer, S., Lorsbach, A., \& Morey, M. (2011). Using a vicarious learning event to create a conceptual change in preservice teachers' understandings of the seasons. Electronic Journal of Science Education, 15(1), 1-14. Received from http://ejse.southwestern.edu/article/view/7381

Chi, M. T. H. (2002). The Processes and Challenges of Conceptual Change. In M. Limón \& L. Mason (Eds.), Reconsidering Conceptual Change: Issues in Theory and Practice (pp. 3-27). Dordrecht: Kluwer Academic Publishers.

Chi., M. T. H. (2008). Three Types of Conceptual Change: Belief Revision, Mental Model Transformation, and Categorical Shift. In S. Vosniadou (Ed.), Handbook of research on conceptual change (pp. 61-82). Hillsdale, NJ: Erlbaum.

Chi, M. T. H., Slotta, J. D., \& De Leeuw, N. (1994). From things to process: A theory of conceptual change for learning science concepts. Learning and Instruction, 33(1), 27-43. http://dx.doi.org/10.1016/0959-4752(94)90017-5

Grant, K., \& Fitzgerald, S. (2005). The Nexus between Teaching and Research: A Qualitative Study Using two Focus Group on Academic Information System Teachers. Electronic Journal of Business Research Methods, 3(1), 37-56. Received from http://www.ejbrm.com/volume3/issue1/p37

Hadjiachilleos, S., Valandies, N., \& Angeli, C. (2013). The impact of cognitive and affective aspects of cognitive conflict on learner's conceptual change about floating and sinking. Research in Science \& Technological Education, 31(2), 133-152. http://dx.doi.org/10.1080/02635143.2013.811074

Hedlund, A., Andersson, I-M., \& Rosén, G. (2009). Attractive Work Process. USE2009: Understanding Small Enterprises-A healthy working life in a healthy business, 20-23 October 2009, Helsingör, Denmark.

Ho, A. (2000). A Conceptual Change Approach to Staff Development: A Model for Programme Design. The International Journal for Academic Development, 5(1), 30-41. http://dx.doi.org/10.1080/136014400410088

Lee, G., \& Byun, T. (2012). An Explanation for the Difficulty of Leading Conceptual Change Using a Counterintuitive Demonstration: The Relationship between Cognitive Conflict and Responses. Research in Science Education, 42(5), 943-965. http://dx.doi.org/10.1007/s11165-011-9234-5

Luthans, F., \& Youssef, C. (2004). Human, Social and Now Positive Psychological Capital Management: Investing in People for Competitive Advantage. Organizational Dynamics, 33(2), 143-160. http://dx.doi.org/10.1016/j.orgdyn.2004.01.003

Mayer, R. E. (2002). Understanding Conceptual Change: A Commentary. In M. Limón \& L. Mason (Eds.), Reconsidering Conceptual Change: Issues in Theory and Practice. Kluwer Academic Publisher.

Markos, S., \& Sridevi, M. S. (2010). Employee Engagement: The Key to Improving Performance. International Journal of Business and Management, 5(12), 89-96.

Mayson, S., \& Barrett, R. (2006). The science and practice of HRM in small firms. Human Resource Management Review, 16(4), 447-455. http://dx.doi.org/10.1016/j.hrmr.2006.08.002

Posner, G. J., Strike, K. A., Hewson, P. W., \& Gertzog, W. A. (1982). Accommodation of a Scientific Conception: Towards a Theory of Conceptual Change. Scientific Education, 66, 211-221. http://dx.doi.org/10.1002/sce.3730660207

Rusanen, A. M. (2013). Towards to An Explanation for Conceptual Change: A Mechanistic Alternative. Science \& Education, September 2013. http://dx.doi.org/10.1007/s11191-013-9656-8

Rusanen, A. M., Pöyhönen, S. (2013). Concepts in Change. Science \& Education, 22(6), 1389-1403. http://dx.doi.org/10.1007/s11191-012-9489-x

Rydell, A., \& Wigblad, R. (2011). Company-level flexicurity during the restructuring process: a model. Transfer: European Review of Labour and Research, 17(4), 547-56. http://dx.doi.org/10.1177/1024258911419781

Sinatra, G. M., \& Pintrich, P. R. (2003). Intentional Conceptual Change. New Jersey: Lawrence Erlbaum Associates Publisher.

Sobreperez, P. (2008). Using Plenary Focus Groups in Information Systems Research: More than a Collection of Interviews. Electronic Journal of Business Research Methods, 6(2), 181-188. Received from http://www.ejbrm.com/volume6/issue2/p209 
Thagard, P. (2012). The cognitive science of science: explanation, discovery, and conceptual change. Cambridge, Massachusetts: MIT Press.

Ulrich, D. (1997). Human Resource Champions: The Next Agenda for Adding Value and Delivering Results. Boston, MA: Harvard Business School Press.

Vosniadou, S. (1994). Capturing and Modeling the Process of Conceptual Change. Learning and Instruction, 4(1), 45-70. http://dx.doi.org/10.1016/0959-4752(94)90018-3

Vosniadou, S. (2003). Exploring the Relationships between Conceptual Change and Intentional Learning. In G. M. Sinatra \& P. R. Pintrich (Eds.), Intentional Conceptual Change (pp. 377-406). New Jersey: Lawrence Erlbaum Associates Publisher.

Åteg, M., Andersson, I. M., \& Rosén, G. (2005). Moviet: motivations-och engagemangsskapande metoder arbetsmiljöarbetet (Moviet: motivation and commitment building methods in work environment). Stockholm: Arbetslivsinstitutet.

Åteg, M., Hedlund, A., \& Pontén, B. (2004). Attraktivt arbete: Från anställdas uttalanden till skapandet av en modell (Attractive work: from employees statements to development of a model). Arbetsliv $i$ omvandling 2004:1, Arbetslivsinstitutet, Stockholm.

Åteg, M, \& Hedlund, A. (2011). Researching attractive work: analyzing a model of attractive work using theories on application attraction, retention and commitment. Arbetsliv $i$ omvandlin (No. 2). Växjö: Linnaeus University.

Özdemire, G., \& Clark, D. B. (2007). An Overview of Conceptual Change Theories. Eurasia Journal of Mathematics, Science \& Technology Education, 3(4), 351-361.

\section{Copyrights}

Copyright for this article is retained by the author(s), with first publication rights granted to the journal.

This is an open-access article distributed under the terms and conditions of the Creative Commons Attribution license (http://creativecommons.org/licenses/by/3.0/). 